\title{
Media Mix as Determinants of Utilization of Development Information in Rural Communities of South-South, Nigeria
}

\author{
Itari Paul Edet Ph.D ${ }^{1}$, Asor Love Joseph Ph.D ${ }^{2}$ \\ ${ }^{l}$ Department of Continuing Education and Development Studies University of Calabar, Calabar, Nigeria \\ ${ }^{2}$ Department of Continuing Education and Development Studies University of Calabar, Calabar, Nigeria
}

\begin{abstract}
This study investigated the extent to which media mix relates to utilization of development information in the rural communities of the South-South zone, Nigeria. The study adopted the descriptive survey design. The population comprised all adult male and female rural dwellers from the three out of six states in the zone (Cross River, Akwa Ibom and Rivers States). A sample size of two thousand, twenty six respondents was selected for the study. Questionnaire was used for data collection. The instrument which was validated by three experts in relevant fields has two parts. Part A elicited the respondents' bio-data while part B consisted of five items to elicit information to answer the research hypothesis. The items were structured on a modified fourpoint Likert scale. In the research area, the instrument was administered personally by the researchers, and with the help of research assistants. Percentages were used to provide information on the respondents' bio-data while ANOVA and multiple regression were used to answer the research question. While Anova determined the joint contributions of the predictors (independent variables), multiple regression analysis indicated the relative contributions of the predictors. The result showed that media mix had significant joint contributions to the utilization of development information. The result showed that the alternate use of local media and face-to-face contact $(B=.164 ; P<0.05)$, alternate use of mass media and face-to-face contact $(B=. .111 ; P<0.05)$ and alternate use of local media, mass media and facet-to-face contact $(B=.163 ; P<0.05)$ had significant positive influence on respondents' utilization of development information whereas, the use of any of the media of communication alone $(B=.028 ; P<0.05)$ without supplementing it with other media has a negative contribution. It was therefore recommended that the proper planning and implementation of rural development programmes and packages requires the use of quality traditional and modern systems of communication simultaneously and alternately.
\end{abstract}

Keywords: Media mix, development information, South-south, Rural communities.

\section{Introduction}

A review of literature here will look at the interactive nature of two dominant models of communication existing in Nigeria's rural environment: the traditional, largely interpersonal and interactive model, and the modern, mass mediated, impersonal system. Drawing from sociological theories of change, one finds that the traditional and modern (mass) communication systems interact in interesting ways as new socioeconomic system evolves within the traditional structures of village life. According to Orewere (1991), "inspite of the imposed foreign language (English) which is the dominant transmission language of the modern mass media, there are significant and complementary outcomes of the interaction between these modes of communication."

Communication, the transmission of information from a point called origin or source to another called destination, receiver or audience, is the bloodstream of every society. Communication is an aspect of culture, the non-material culture. Indigenous and traditional communication modes and channels have a sort of cultural relativity. Therefore, traditional mode and channels should be identified, assessed, understood and applied in the context of a particular culture and its value system. In Nigeria, the indigenous and traditional community modes and channels tend to have variations from one cultural region or ethnic group to another. The modes and channels reflect the social structure of each community. Such social structure is similarly determined by totality of the historical and economic experiences of the people (Orewere, 1991). Face-to-face, interpersonal and group communication which are the basic ingredients of traditional modes function both vertically and horizontally and are natural, real and inevitable in a community's planned and unplanned development. They have also proved very useful in the task of solving community and individual problems. This has been documented in the field work experiences in the dissemination of attitudinal change-directed information, especially of new farm practices in the rural areas. Itari et al (2015), Emenyeonu (1987), Orewere (1984), Bogunjoko (1980), Alao (1975) and Williams and Williams (1969) corroborated this perspective.

Mass media on the other hand, have often been regarded as the possible panacea for many of the development problems of the third world. The have often been accepted as the major sources of knowledge, its dissemination and utilization, and as representing potential direct channels of influence and information transfer 
Media Mix as Determinants of Utilization of Development Information in Rural Communities of ..

from researchers and experts of various sorts to a great majority of consumers (Orewere, 1991). The question to ask here is that, what then has been the function of mass media in the rural areas when compared with the role of indigenous and traditional communication channels?

First, as Orewere (1991) point out, the mass media, especially battery-operated radio sets, mobile cinemas and, in the few electrified areas, television sets, have had some effects both on adults and on children and adolescents. This is because the mass media have continued to play an important role in the transmission of knowledge and information, cultivation of beliefs, campaigns and development, antisocial behaviour and sex role socialization.

Second, limitations notwithstanding, the mass media seem to have some influence in agenda setting, political socialization, response to advertisement, increase consciousness of nationhood, and knowledge of other parts and cultures of the country.

Third, the presence of mass media acts a catalyst in the willingness and ability of the rural people to learn to read and write at a functional level in the media language. Basic formal education becomes mandatory and a drive that has never been in the priority objectives of traditional communication channels.

Fourth the mass media in establishing the direct contact with individuals, by pass the traditional communication in issues such religion, politic education, commerce and the economy. Fifth, the mass media amplify the voices of the political leaders, persons occupying powerful positions in other sectors of national life and of prominent intellectuals.

From the foregoing, it may not be out of place to examine an on-going lively debate on which choice to make - traditional or mass media - in planning or providing development information given the fact that both media have demonstrated a capacity of mobilizing people for development. Many scholars have however argued in favour of the traditional communication channels, pointing out its power to capture people's imagination and subsequently change behaviours. Soola (1984) for instance, has pointed out that, since people's lives, particularly in the rural areas, are rooted deeply in their tradition, and that since the language they understand is the one that exploits the rich imagery of their cultural milieu, utilization of the mass media communication will constitute a threat to the ability of the media to transmit cultural, political and educational messages necessary for socio-economic development. Itari (1994), has also argued favourably for the use of traditional media by pointing out that "traditional forms of communication like folksongs, plays or sermons have a credibility and meaningfulness in the culture which no imported technology can have."

These qualities show that indigenous communication holds bright promise for development. This is however not to say that indigenous channels can solve all development problems. As Soola (1984:133) observes "it is important to realize that traditional media alone cannot carry the burden of communication for national development." And as Akinleye (2003:69) put it, "no communication strategy or medium can." This implied that indigenous communication has limitations. The reach of its channels is limited; some channels are also time consuming, especially oral channels which require the physical presence of an audience.

Given this and other weaknesses, it becomes obvious that indigenous communication alone may not be able to fulfill all the development needs of the people. In search of alternatives to indigenous media, quite a number opinion has been proffered. The use of mass media is one of such ideas. Until recently, emphasis had been on the use of mass media for propagating development information. The mass media - the print, radio, television and cinema - are a powerful force as educators, agitators, mobilizers, motivators and entertainers. They can create a feeling of involvement and participation. It is through them that the national agenda of the day is presented to the people.

However, some of the weaknesses of the mass media make them antithetical to development. The print media for instance demands not only a regular financial involvement but also a great deal of intellectual effort. This requirement makes the print media unsuitable for development communication in Nigeria with a predominantly illiterate population, transportation problems and dispersed rural population (Soola, 2003; 1984). Television on other hand, though possesses peculiar positive characteristics of sight, sound and motion- quality is still not within the financial reach of the uneducated poor. Also, television is electricity dependent which explains why in Nigeria, there are just a few television sets found in the rural areas. Not these, most mass media cannot meet a number of standards outlined by the Food and Agricultural Organization (FAO, 1987) for evaluating a development medium.

If the mass media are also deficient in the quest for evolving and appropriate communication system that can satisfy the needs of development in the rural areas, what then is the way forward? In an attempt to provide an answer to this question, a number of scholars have called attention to the importance of utilization of media mix approach as a solution to the problem of finding an adequate media strategy for rural development. For instance, Moemeka (1980:167) observes that, "recent thinking on the use of the media for education and public enlightenment strongly favours a multi-media approach." This is because, some media are best suited for certain activities than others (as shown in this review). Supporting this view, Akinyele (2003) believes that, the interaction between two media brings out a result greater than what both of them could achieve had they worked 
separately. He therefore advocates a marriage between mass media and indigenous media for effective information delivery be it in the rural or urban sector. The reason being that, while the mass media have the reach and speed, the indigenous media have the credibility, communal ownership and popular participation. In the same vein, Soola (1999), calls for "an integration of traditional and mass media of communication" in Nigeria where development usually involves the local people (who often are poor, less educated and socially immobile), and the providing agencies who usually want to reach the people with new innovations, ideas or messages.

A number of studies give credence to this view. In a survey, Wilson (1988) sought to assess traditional -modern communication as practices in old Calabar. He studied the different instrument media and channels of communication available and used in the area. The study also examined the nature and structure of traditional communication systems as well as the strategies for the modern media. Finally, he looked at the relationships between traditional and mass media channels of communication and whether demographic factors and income had any effect on the people's use and acquisition of media hardware,

He found that traditional media instruments were still being used to communicate with the people. The use of mass media for information needs, Wilson (1988) notes, was for actualization, mobilization, education, liberation and development. Thus, the study supports the combined use of traditional media with mass media for effective communication.

Barsisa (1988) in a study asserts that radio is more popular with both the rural masses and urban dwellers for diffusion of ORT and EPI messages though the respondents pointed out that the mass media are more urban- based than rural based. Thus, he found that interpersonal channels play a more important role in the rural areas than the urban areas, and submits that it might be due to inaccessibility of the modern media facilities to the rural masses,

In a case study of two Ghanian villages, Bosompra (1987) looks at sources of health information among rural dwellers in Africa. This study also sought to know if the people knew about cholera, HIV/AIDS, ORT, water treatment and mass immunization campaigns launched by the Ghanian Health Ministry. He found that conversation was the most popular method but the least trusted as source of information, radio, was the second most trusted and popular source of information while health officers were the most trusted but third most popular source of health information. Other sources like the church, market places and newspapers played significant roles. The research finding however, was doubtful of the activeness of traditional sources like town crier, songs and dances, traditional theatre etc. in the rural communication system. However, he concluded that given the high credibility rating accorded radio and interpersonal sources among the people, there is no other option than a call for a careful blend of mass media with traditional/oral communication system for the dissemination of messages in such vital matters as health.

Gilluly and Moore (1996) reported the evaluation of the Isfahan pilot project in Iran in 1970- 1971. According to them, it was one of the first research-oriented family planning communication projects. Its aim was to educate people on family planning through two campaigns. One of these was radio only while the other used multimedia approach. The number of contraceptive users increased by $18 \%$ during radio only campaign. After the two campaigns, clinic reports showed $61 \%$ increase in the number of contraceptive users among other things. In addition, they also reported an evaluation of a family planning radio programme in Egypt. After four years of broadcast, an evaluation carried out by the University of Chicago showed that the broadcast "increased knowledge of family planning but did not necessary increase use of contraceptive" (p. 869) (Ojebode, 2002).

\subsection{The Problem}

Past studies on the use of media information for development especially rural development have dwelt on channels, amount, type and quality of communication necessary to support development initiatives and objectives. Some of these studies have also emphasized the impact of media use as provided in rural development packages and programmes, indicating the level of effectiveness or otherwise of these media. However, there is limited information and research on media mix as it determines the utilization of development in Nigeria especially the South-South region. It is for this reason that the present study was undertaken.

\subsection{Purpose}

The purpose of this study was to find out the extent to which Media Mix determine Utilization of Development Information in the rural communities of South-South goe-political Zone, Nigeria.

\subsection{Significance}

The primary audience/ beneficiary of a work like this at the local people. The work is designed to be part of a consciousness raising and consciousness changing process ongoing in planning and strategizing schemes for the rural people and rural areas. Consequently, the research is specifically intended to: 
(i) Influence the political process because, it is designed to be received, read, understood and acted upon by those in policy making circles in Nigeria and Africa.

(ii) Contribute to the development process by helping the change agents and their agencies in carrying out their work and,

(iii) Provide feedback into development information planning and practice and help the general public to know the role of information in development experiment.

\subsection{Research hypothesis}

There is no significance relationship between media mix and utilization of development information among rural dwellers of South-South Goe-political Zone, Nigeria.

\section{Methods}

The study which adopted the descriptive survey design, aimed at investigating the extent to which media mix relates to the utilization of development information in the three selected states of Cross River, Akwa-Ibom and Rivers out of the six states in the South-South Goe-political Zone of Nigeria. A sample of two thousand and twenty six respondents' was selected from a population of about 171,309 adult residents.

\subsection{Instrument for Data Collection}

Data was collected using questionnaire which was validated by experts in Measurement and Evaluation in the University of Calabar, Nigeria. This was complemented with 18 Focused Group Discussions (FGD) with the rural dwellers. The questionnaire which was administered personally by the researchers and with the help of trained research assistants and retrieved immediately was structured on a modified four-point Likert scale of strongly Agree (4), Agree (3) Strongly Disagree (2) Disagree (1)

\subsection{Method of Data Analysis}

Simple percentages and frequency counts were used to evaluate and analyze the bio-data information while ANOVA and multiple regression were used to measure and determine the joint and relative effects of the predictors (independent variables).

\section{Results}

The result of the study were presented on tables 1 and 2 below;

Table 1: ANOVA on the joint contribution of media mix to the utilization of development information among rural dwellers.

\begin{tabular}{|l|l|l|l|l|l|}
\hline Source of variation & Sum of square & D f & Mean square & F & Sig. \\
\hline Regression & 978.680 & 4 & 244.670 & 52.610 & .000 \\
Residual & 9398.874 & 2021 & 4.651 & & \\
Total & 10377.554 & 2025 & & & \\
\hline $\mathrm{R}$ & $=.307$ & & & \\
$\mathrm{R}^{2}$ & $=.0 .94$ & & & \\
Adj $^{2}$ & $=.0 .93$ & & & \\
\hline
\end{tabular}

$*$ Significant result $\left(\mathrm{F}_{(4,2021)}=52.610 ; \mathrm{p}<0.05\right)$

The result in table 1 above shows that a combination of two or more media (media mix) had significant joint effect on the utilization of development information among rural dwellers $(F=52.610 ; p<0.05)$. Thus, the null hypothesis above is rejected and an alternative hypothesis is upheld.

Apart from the joint effect of the independent variables, a further test was carried out using multiple regression method to determine the relative effect of the predictors on the utilization of development information among rural dwellers. Table 2 below shows the relative effect of the predictors on the dependent variable (utilization of development information among rural dwellers).

Table 2: Summary of regression analysis showing relative contributions of media mix to the respondents' utilization of development information.

\begin{tabular}{|l|l|l|l|l|l|}
\hline Factors & B & Std. Error & Beta & t & Sig \\
\hline Constant & 9.474 & .288 & & 32.871 & .000 \\
\hline $\begin{array}{l}\text { Alternative use of local media and face-to-face } \\
\text { contact }\end{array}$ & .462 & .063 & .164 & 7.351 & .000 \\
\hline Use of any of the medium alone & $6.711 \mathrm{E}-02$ & .051 & .028 & 1.328 & .184 \\
\hline $\begin{array}{l}\text { Alternative use of mass media and face-to-face } \\
\text { contact }\end{array}$ & .262 & .051 & .111 & 5.082 & .000 \\
\hline Simultaneous and alternate use of mass media & .443 & .061 & .163 & 7.237 & .000 \\
\hline
\end{tabular}


The result from table 2 above shows that the alternative use of local media and face-to face contact $(\beta=$ $.164 ; \mathrm{p}<0.05)$, alternate use of the mass media and face-to face contact $(\beta=.111 ; \mathrm{p}<0.05)$ alternate use of the local media, mass media and face-to face contact $(\beta=.163 ; \mathrm{p}<0.05)$ had significant positive influence on the respondents' utilization of development information. However, the use of any of the media of communication (for example using print, radio, television or indigenous media alone) without supplementing it with other media had a negative contribution to the utilization of development information.

Based on the results on tables 1 and 2, it is evident that the one of two or more media had significant effect on the utilization of development information among rural dwellers. Thus, the null hypothesis above is rejected and an alternative hypothesis is upheld

\section{Discussion of findings}

A number of studies have corroborated the above findings that, a significant relationship exist between media mix and utilization. Akinyere (2003), Soola (1999) and Meoemeka (1980) have indicated in their studies that no single medium of communication has been able to carry the burdens of development alone. That while the mass media have the reach and speed; the indigenous media have the credibility, mutual ownership and popular participation. Therefore, they caution that an adoption of the mass media or indigenous folk media alone might constitute a threat to the ability of the media to transmit the required messages needed for development. This is why each of them believes that the interaction between two or more media (as indicated in the finding above) brings a results greater than what both of them could achieved had they worked separately.

Furthermore, Bosompra (1988) in a study of two Ghanian villages, looked at sources of health information among rural dwellers in Africa. He concluded that given the high credibility rate accorded radio and interpersonal sources among the people, there is no other option than a call for a careful blend of mass media with the traditional/oral communication system for the dissemination of messages in such vital matters as health. Also, in a survey, Wilson (1988) sought to assess traditional - modern communication as practiced in old Calabar. He studied the different instrument media channels of communication available and used in the area. He found that traditional media instruments were still being used to communicate with the people. The use of mass media for information needs, was for actualization, mobilization, education, liberation and development. Thus, the study supports the combined use of traditional with mass media for effective communication.

In combining the channels of communication as suggested above by the different scholars, Emereuwaonu (1980) advises that, it is necessary that those engaged in introducing innovations in the rural areas should have at the back of their mind the culture of the people in question. And as a consequence ask the following question;

- How much of the audience do we want to cover - as we concentrating on the entire rural audience, or its leadership, the educated, illiterates, the farmers, fishermen etc.

- What do we intend to achieve e.g. creation of general awareness, detail information, or motivation to undertake or join hands in rural development etc.

- How long does the message stay before the audience?

- What are the costs of the personnel for exposing the people?

- How many of the communication channels are available for use?

It is difficult to ascertain how much of communication is needed for rural development. What is certain however, is that frequent accessibility to sources of relevant and digestible information through mass and interpersonal channels is a prerequisite to rural development.

While Moemeka (1980) believes that the choice of a medium or media is usually a difficult one because of prejudices and the tendency to stick with the known, making such a choice, he says is very important because, according to him on it depends.

- Whether or not the target audience in the rural areas is, in the first instance, reached.

- On it too, depends to a large extent, whether the individual members of the population will make the initial effort of granting their attention.

- Choice of media also affects what people learn and how quickly and how well they learn it.

Similarly, Yarhere (2003:134) is of the opinion that: "Infrastructural consideration has to be made when choosing what media channels to employ in a particular campaign for a rural community. Power supply to rural set-up is epileptic even where the infrastructures have been installed". Again, Moemeka (1980) cautions that, in examining the media situation in the country to determine ways by which the media can be effectively and efficiently utilized for rural development, the following things should be taken into consideration, namely; it is necessary to take a general look at the media, their characteristics and their strengths and weaknesses.

Also, in the course of the various Focus Group sessions held participants confirmed that the use of one media alone could constitute a threat to development. The sessions extensively illustrated how different 
combinations of communication media can be used to achieve effective information transfer and improvement in the productive activities of the people. The view that the rate of rural development depends on the handling of information was supported by the participants. Most especially, the participant pointed out that communication effectiveness is achieved and utilization readily enhanced if, and when the different media channels are combined or made to function in the following ways.

- When there is consistency in the messages delivered. That is, when all the media channels are saying the same thing.

- When the intensity of a particular message is high. That is, when all the media channels are made to concentrate on a small rather than diverse issues. Examples cited was the ongoing media campaigns on HIV/AIDS awareness where the radio, television, newspapers, health personnel, town crier etc. are all effectively employed.

- When issues, messages, viewpoint etc. are repeated frequently over and over by the different media channels either at the same or different times.

- Finally, participants said utilization of development information is enhanced when messages are properly timed. That is, considering the fact that most of them are farmers, messages should be aired at the right time and place.

This finding corroborates further the Social Theory of communication by emphasizing that, communication messages be combined in appropriate order for particular social groups (the rural dwellers), instead of expecting universal reaction from all members of the society. Therefore, the theory recognizes communication (media mix) as a potential tool for social changes and development in the rural areas.

\section{Conclusion}

In Nigeria, evidence abounds everywhere where straight jacket development packages imposed on the people from outside (government or donor agencies) have failed. Such programmes have demonstrated frequently not to interest, engage or benefit the rural people. The various Farms Settlements, River Basin Authorities, Operation Feed the Nation (OFN), Green Revolution (GR), Directorate for Food, Roads and Rural Infrastructures (DIFRRI), Better Life, etc are a few examples of failed attempts at rural development in Nigeria. Realizing therefore, that without communication, which can motivate participation of the people in the development exercise, has led to the emphasis in this study on the role of communication in Nigeria's rural development. On the basis of this, the study is of the opinion that a marriage of the traditional communication with the mass media is the only effective and efficient way to bring about the much needed rural development in the country.

\section{Recommendations}

In other to avoid the habitual top-down approach relationship between the providing agencies and the local people, and in other to avoid waste and aborted dreams in development efforts and practice, the following policy guidelines and recommendations are hereby made:

i. The success of rural development programmes rest squarely on the availability of quality information by rural development worker and rural people.

ii. Governments and other providing agencies should explore and make use of local structures including the people's language and indigenous media already in place in the communities to partner with rural people in their development policy formulation and practice.

iii. The traditional and modern systems of communication as currently organized, cannot operate independently to bring about development in Nigeria's rural areas. The solution seems to lie in symbiotic association of the traditional with modern communication systems.

\section{References}

[1]. Akinleye, L. (2003). Indigenous Knowledge Systems, Communication and Sustainable Development (IKSSD) in Soola, E. O. (Ed). Communicating for Development Purposes. Ibadan: Kraft Books Ltd.

[2]. Alao, J. A. (1975). Characteristics of Farmers Who Utilize Agricultural Innovations in Nigeria, Journal of Rural Economics and Development. $9(1)$

[3]. Bogunjoko, I. O. (1980). Relationship of Socio-economic Characteristics of Farmers and Use of Extension Workers and Radio as Sources of Information on Improved Farm Practices in Giwa District of Kaduna State, A Paper Presented at a Seminar on Change in Rural Hausaland. Kano

[4]. Emenyeonu, N. B. (1987). Communication and Utilization of Agricultural Innovations: Qualifications and Notes Towards a Conceptual Model. Africa Media Review, 1, (2).

[5]. Emereowaonu, E. U. (1980). Communication Strategies for Rural Development. A Paper presented at the National Conference on integrated Rural Development and Women in Development, University of Benin, Benin City.

[6]. FAO (1984). Development Communication Paper: Perspectives on Communication for Rural Development. Rome: FAO

[7]. FAO (1994). Communication: Key to Human Development. Rome, FAO

[8]. FAO (2005). Realistic Approaches to Support Information and Communication. File://A:/Communication. htm. 
[9]. Gilluly, R. H. \& Moore, S. H. (1996). Radio- Spreading the World in Family Planning. Population Report. Pp 853 - 887.

[10]. Itari, P. E. (1994). Policy and Practice of Community Development in Cross River State, Nigeria: A Case Study of Selected Development Projects in Akamkpa Local Government Area An M.Ed. Thesis of the Department of Adult Education; University of Ibadan, Nigeria.

[11]. Itari P. E., Beshel, C. A. \& Okeme I. (2015) Indigenous Communication Media and Utilization of Development Information in Rural Communities of South-South Nigeria. International Journal of English and Literature (IJEL) 4(6).

[12]. Moemeka, A. A. (1980). Integrated Rural Development in Bendel State: The Role of and Strategy for Mass Communication. Paper presented at the National Conference on Integrated Rural Development and Women in Development, University of Benin, Benin City. Sept. $22-26$.

[13]. Ojebode, A. (2002). Radio as a Development Communication Medium: Types, Formats, Roles and Limitations in Soola, E. O. (Ed.) 2003 Communicating for Development Purposes Ibadan: Kraft Books Limited.

[14]. Orewere, B. (1994). Impact of Agricultural Broadcasting on Farmers in Jos and its Environs, M.Sc. Thesis, Ahmadu Bello University, Zaria.

[15]. Orewere, B. (1991). Possible Implications of Modern Mass Media for Traditional Communication in a Nigeria Rural Setting. African Media Review 5(3) pp. 53-65.

[16]. Soola, E. O. (ed) (1984). Communication Policy and National Planning. Rural Development in Nigeria 1(2) pp. $131-149$.

[17]. Soola, E. O. (2003). Communicating for Development Purpose. Ibadan: Kraft Books Ltd.

[18]. Soola, E. O. (1999). Traditional and Modern Communication Media Use and Strategies for Effective Environmental Awareness. Journal of Communication and Language Arts 1, (1). Pp. 32-44.

[19]. Williams, S. K. T. \& Williams, G. E. (1984). Sources of Information on Improved Farming Practices in Some Selected Areas of Western Nigeria, Bulletin of Rural Economics and Sociology, 4, No. 1.

[20]. Wilson, E. W. (1988). A Survey of Traditional Modern Communication Systems in Old Calabar Province (1846-1986) Ph.D Thesis of the Department of Communication and Language Arts. University of Ibadan, Nigeria.

[21]. Yarhere, M. T. (2003). A review of Development Communication Strategies for Third World Rural and Urban Settings in Soola E. E. O. (Ed.) Communicating for Development Purposes Ibadan: Kraft Books Ltd. 